\title{
A Study of Taishan Shigandang Culture in English Literary Records
}

\author{
Fen Tian \\ School of Foreign Languages and Literature, Tai Shan University, Tai'an, China \\ Email: susanhai227@163.com
}

How to cite this paper: Tian, F. (2021). A Study of Taishan Shigandang Culture in English Literary Records. Advances in Literary Study, 9, 189-196.

https://doi.org/10.4236/als.2021.94020

Received: September 22

Accepted: October 18, 2021

Published: October 21, 2021

Copyright $\odot 2021$ by author(s) and Scientific Research Publishing Inc. This work is licensed under the Creative Commons Attribution International License (CC BY 4.0).

http://creativecommons.org/licenses/by/4.0/

\begin{abstract}
Language is the carrier of culture and culture influences language, whereas their relation is not static but dynamic which can be indicted from the Shigandang Cultural records in the English language. As an important folk culture, Taishan Shigandang was believed to ward off evil spirits, protect people and keep security. And this belief can be found in the English literary records about Taishan Shigandang. This paper is to describe the cultural development in Taishan Shigandang studies in the English records, then search for the similarities and differences between the Shigandang culture in English and Chinese after a historical analysis. Finally, an explanation is provided to fully understand Shigandang culture.
\end{abstract}

\section{Keywords}

Taishan, Shigandang, Language and Culture

\section{Literature Review about the Study of Taishan Shigandang}

The relationship between language and culture has always been inseparable as language carries culture, and culture affects language. Furthermore, the relationship between them is dynamic and developing, just as Du Daoming put forward "Language is not only a cultural phenomenon, but also a living fossil of history and culture. It plays an irreplaceable role in the construction and inheritance of culture and the communication between different cultures; on the other hand, different cultural characteristics often lead to different language characteristics (Du, 2008)." This paper makes an analysis of the folk culture of Taishan Shigandang, which intensively appeared in English documents from the middle and late 19th century to the middle of the 20th century, in order to show the image of Taishan Shigandang described in English, so as to explore how 
English describes the image of Shigandang, what are the similarities and differences between English and Chinese Shigandang culture, and what are the reasons for the differences.

Shigandang, also known as Taishan Shigandang, is a major feature of Taishan folk belief and the focus of experts and scholars. Professor Ye Tao published Taishan Shigandang in 2007 (Ye, 2007) which discusses in detail the context, overseas dissemination and various related customs and legends of Taishan Shigandang. He believes that "the auspicious peace culture expressed by Taishan Shigandang reflects people's general desire for peace and harmony, and shows the humanistic spirit and cultural creativity of the Chinese nation". Professor Zhou Ying discussed the historical development of Taishan Shigandang from being banned and abolished to carrying forward (Zhou, 2015), and put forward that Taishan Shigandang, which has been inherited for thousands of years, reposes people's good wishes for peace, auspiciousness and health, and their sense of historical responsibility as "being able to take responsibilities".

From the above, it is not difficult to see that Taishan Shigandang is not only an important folk belief deeply rooted in people's hearts, but also has a sense of time and responsibility. Similarly, this can also be found in English literary records with the corresponding same and different expressions.

\section{Lists and Descriptions of Taishan Shigandang in English Literary Records}

The earlier record of Taishan Shigandang can be traced back to 1869, when John Livingstone Nevius in his book "China and the Chinese" (Nevius, 1869) stated:

A house standing at the terminus of a street or alley where the road branches off on each side, is supposed to be subjected to the same evil influence, from the stream of bad luck flowing along the street and beating against it. A stone slab is generally seen erected at such places bearing the inscription Tai shan shih kan tang-"I am, or I represent, the Taishan rock, and am not afraid to withstand you." Taishan is the name of one of the largest and most celebrated mountains in the empire; and as a solid mountain not only withstands all evil influences, but is the source of those which are auspicious, this name is used as a charm to frighten back the adverse tide of evil. No one ever supposes that these stones came from Taishan, and it is amusing to see the inscription sometimes on a brick.

Later, Shigandang was consistently the focus and interestingly described.

W. O. Elterich (Elterich, 1894) said that Taishan's sacredness may be seen from the fact that the Chinese regard simply a brick or stone from this mountain when set up at the end of a street as sufficient to drive away all evil spirits who would desire to use the street as a path way. Quite frequently one can see in the wall opposite the end of the street, instead of the customary shrine, a brick or stone with the inscription, "Mt. Tai can withstand you (Elterich, 1894)."

Frederick Brown (Brown, 1908) described: all over China there are stones placed at the side of rivers where they are liable to break their banks, facing 
dangerous rapids, at crossroads, and facing the entrance to public and private buildings. The stones are of various sizes, shapes, and designs. They are surmounted by the head of a monster; below are the characters Tai-Shan-Shih (this stone is from the Tai mountain). The Chinese say that no demon will face such a monster, who guards the way to any dwelling, crossroads or rapids. The origin of this superstition is as follows: on the highest peak of Tai-Shan (one of the five sacred mountains of China) there is a god who decapitates demons, whose name is "Kan-Tang", and any stone carried from Tai Shan with Kan Tang's figure engraved thereon can destroy or oppose demons and drive away disease (Brown, 1908).

Emily G. Kemp wrote a book named The Face of China (Kemp, 1909) after her travel around. She noticed Shigandang and depicted: Stones are carried from it to all parts of the province, and when a house is built with an unlucky aspect-namely, facing a cross-road or a turning-one of these stones is built into the wall, with an inscription, "The stone from Tai Shan accepts the responsibility (Kemp, 1909)."

The further discussion and deeper understanding of Shigandang were by George Evans Moule (Moule, 1912) after his talking with Emmanuel-èdouard Chavannes who did a great contribution to the study of Taishan. Moule used the Chinese characters 泰山石敢當 to regard it as a formula, "carved on stone, brick, or wood and sometimes surmounted by a tiger's head is fixed to a house which stands opposite the end of a street or lane as a charm against evil influences which may come unchecked by any corner down such street or lane. There used to be specimens of such charms in the Nanking Road and other parts of the Foreign Settlement at Shanghai. There is also evidence that in the fourteenth century the three words Shih kan tang 石敢當 alone were used, and Dr. de Groot seems to think that this is even now the more common form, so that it is quite possible that the charm had originally no connexion with Tai Shan. There is also evidence that a little figure was used in place of the inscribed stone and Shih is more than once explained as a personal name. In a village in the south of Tai An district I know a (seemingly Buddhist) figure carved on a block of stone opposite the end of a street. The formula Tai Kung chih tzu 太公至此 which certainly refers to a person is used in a similar way. The longer form Taishan Shih Shen kan tang 泰山石神敢當 is also used (Moule, 1912).”

Heinrich Hackmann (Hackmann, 1914) compiled a book after his travel, in which Taishan Shigandang was illustrated as "Taishan shih Kantang", i.e., "Taishan dares to defy the evil spirits". And the rock from this hill (Taishan) let into the remotest walls of houses in the furthest parts of China. Furthermore the carrying away of pieces of rock and putting them up again else whereto ensure by their presence the banishment of evil spirits even can remind one of the story in the old testament of how the tables of stone were given to the children of Israel on Mount Sinai, and how they carried them about with them in the ark as a visible sign of the omnipresent God (Hackmann, 1914).

In 1917, after Florence Wheelock Ayscough (Ayscough, 1917) visited Taishan, 
she gave a speech about the sacred mountain and in it, some words were about Taishan Shigandang since the pilgrims who desire protection for their houses have but to place in one of their outer walls a stone upon which are cut the characters Taishan shih kantang. These stones are found all over the country. She noticed that some Shigandang were depicted on the screen stands on the Sinza Road, while she believed that these were slightly different forms in far off Ssü Ch'üan (Ayscough, 1917).

In 1919, Guy Morrison Walker (Walker, 1919) described Shigandang as a memorial by the pilgrims who visited the sacred mountain and carried back the stone all over the country. And usually, the stone bears an inscription substantially as follows: "Look on this and think of the Sacred Mountain (Walker, 1919)."

Charles Keyser Edmunds (Edmunds, 1919) even quoted the remarks about Taishan Shigandang to show the stone's sacredness and popularity. "In all the cities and villages of Shantung and even in adjacent provinces, stones from Tai Shan are much in demand as talismans. It is believed to be unlucky for a house to be so built as to face a turning or a cross-road. To ward off evil spirits, stones from Tai Shan are inserted in the wall of the house so situated, with the inscription, a stone from Tai Shan. Who dares come this way (Edmunds, 1919)?”

J. Benjamin Caulfield (Caulfield, 1921) saw the essential meaning of Taishan Shigandang and translated it as "The Stone Will Protect". He noticed that the stone was supposed to possess miraculous powers. And it was once a custom to carry away a stone from the mountain and build it into a new house as a sort of protecting charm. The magic Tai Shan inscription had attributed to it the same power. It was not an uncommon sight in China to see a "cornerstone" bearing the words:

TAI

SHAN

SHIN

KAN

TANG

with the meaning "The stone of Tai Shan will protect you from all harm (Caulfield, 1921)."

Carl Crow again quoted the words (Crow, 1921) about Shigandang "In all the cities and villages of Shantung, stones from Tai Shan are much in request as talismans. It is believed to be unlucky for a house to be so built as to face a turning or a cross road. To ward off the ill luck, stones are inserted in the wall of the house so situated, with the inscription 'The stone from Tai Shan accepts the responsibility." Such stones have been found in every province in China (Crow, 1921).

In 1926, William Edgar Geil told the story of Taishan Shigandang (Geil, 1926) as a scholar ${ }^{1}$ and a hero in the short 5 dynasties, and he wrote the following:

${ }^{1}$ Once, the character scholar was supposed be both literati and warriors, but when Geil told the story of Shigandang, it in fact referred to a warrior, who protected the king bravely and vigorously. 
400 years after his self-sacrifice, the tablets were to be found in every city with the inscription Shih Kang Tang. It would appear that then the memory of the man began to fade, and as the tablets were originally made of stone brought from Tai Shan, its name was prefixed. Thus the tablets bore the characteristic and symbolic 5 characters, Taishan Shih Kan Tang: "This stone from Taishan can ward off [evil spirits]." And their virtue came to be more and more associated with the magic power of the Sacred Mountain.

Geil also proposed a picture of Taishan Shigandang (Figure 1):

The ideographs have been freely translated: "I am Taishan, you dare not run over me." Compare with the stone of the diagrams at Sung Shan.

\section{Discussions and Findings}

It can be seen from the above that the image of Shigandang described in the English literature has the following common points:

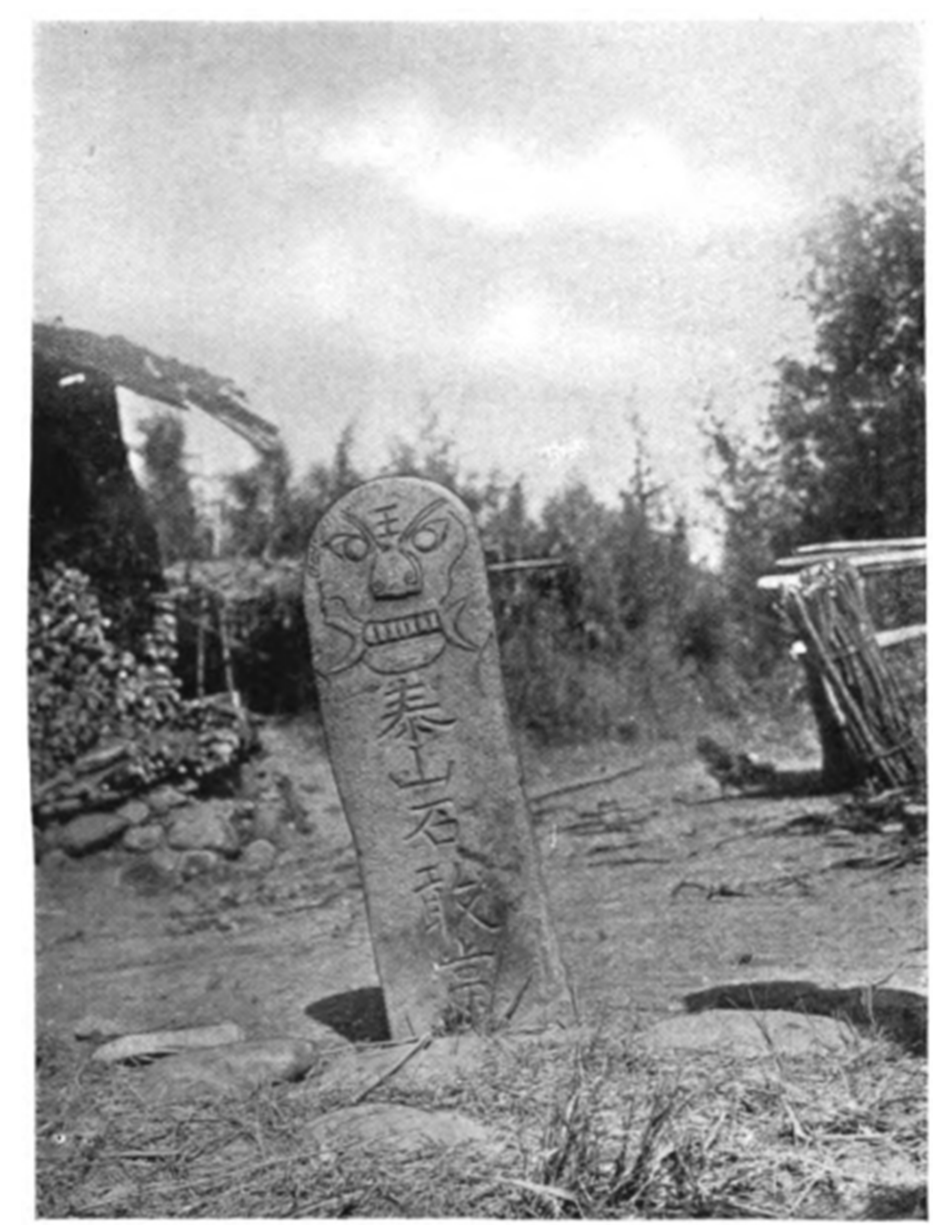

A TAI SHAN STONE, PHOTOGRAPHED BY WILLIAM EDGAR GEIL. IN NOVEMBER A.D. 1909, NEAR STONE FACE VILLAGE, KWANGSL

The 5 ideographs have been freely translated: "I am Tai shan: you dare nc run over me." Compare with the stone of the 5 diagrams at Sung Shan.

Figure 1. A Tai Shan stone, photographed by William Edgar Geil in November a.d. 1909, near stone face village, Kwangsl. 
1) The image of Shigandang placed on the roadside, the crossings, the corner of house, and the walls at the intersection and bridge mentioned in the literature is consistent with the position of traditional recorded Shigandang culture in Chinese.

2) The literature authors all agree that Shigandang is the stone taken from Taishan or associated with the sacred mountain although some are mentioned as not stones but wood or brick. Whatsoever, Shigandang is called Taishan Shigandang.

3) The literature believes that the function of Taishan Shigandang is to exorcise demons and ward off evil spirits so as to protect houses and human beings.

4) Most articles mention that Taishan Shigandang is widely spread throughout the whole province and the country, so the influence of the sacred and magic stone can be hinted.

However, there are some special differences worth mentioning:

1) John Livingstone Nevius (Nevius, 1869), W. O. Elterich and Frederick Brown closely link Shigandang with Taishan, that is to say, the sanctity of the stone comes from the sanctity of Taishan: being holy, exorcising evil spirits. It is the most sacred and famous mountain in the country. On the top of the mountain are living gods who could subdue demons. So the stones possess the magic power.

2) For the role of Shigandang, Frederick Brown also mentions that Taishan Shigandang can cure diseases; Kemp thinks it accepts responsibility; Walker thinks it is a monument used by pilgrims to commemorate, while Mrs. Ayscough; Charles Keyser Edmunds and Carl Crow think Taishan Shigandang also has the role of talisman.

3) Frederick Brown believes that Shigandang belief was a superstition; Moule mentions that Shigandang has a Buddhist image, “太公在此” can play the similar role; Huckman associates the magic stone with the ten commandments of Moses in the Old Testament because of his bravery; Geil tells the story of Gandang to save the emperor in the five dynasties.

As to the reasons for these differences, they are closely related to the origin of Taishan Shigandang and its corresponding myths and legends.

First of all, Shigandang must be connected with Taishan, which is originated from the ancient mountain spirit of stone worships. Taishan is full of magic power and holiness because of its unique historical status of the five sacred mountains in China: the legendary belief in controlling life and death, the historical records of the emperors' Feng and Shan ceremony, and the historical facts of people's pilgrimage from far and near. It naturally obtains "The safety of Taishan brings peace to the world"2. Therefore, the stones (or plants) of Taishan are full of spirituality, which can exorcise demons, ward off evil spirits and en- 
sure peace.

Secondly, no matter it is "Taigong is here", Taishan Shigandang is to treat patients and save people or Gandang as a warrior of rescuing the emperor during the five dynasties, the records of Shigandang are related to the folklore of Shigandang in Taishan. It is said that the warrior (also known as Hercules) who rescued the emperor in the Five Dynasties, was not a scholar at all. This is a misreading of Shigandang culture. It may be because the "Scholar" in ancient books not specifically refers to warriors, but also literati and scholars as well. In this way, there are many explanations for the inheritance of Chinese traditional culture. In addition, it is difficult to find equivalent words in English culture, so misreading is inevitable.

In addition, Frederick Brown regards the belief of Shigandang as a superstition. From the 19th century to the mid-20th century, it was particularly common in English literature because the authors were biased against Chinese culture from the standpoint of western culture and religion and regarded folk beliefs as superstitions. Professor Zhou Ying also mentioned this: “After history entered modern times, influenced by Western civilization, folk customs such as Shigandang were regarded as superstitious.” (Zhou, 2015) For Moule's reference to seeing an image that looks like a Buddhist figure in the southern suburbs of Tai'an, it is difficult to judge due to the lack of evidence, but there is no doubt that Taishan Shigandang was influenced by Buddhism in its development process. For example, the earliest stone Gandang monument found in Fujian was established by Buddhist disciple Lin Jinhui in Shaoxing in the Southern Song Dynasty.

Finally, just like Hackmann's connection to the stone tablets engraved in the Old Testament because of the stone's boldness, such a connection is also very common in English documents. For example, when Geil talked about the city of Tai'an at the foot of Mount Tai, he contacted the holy city of Jerusalem in Babylon, Cuba (Geil, 1926). Due to the differences between English and Chinese languages and cultures, when it is difficult for one culture to find a complete equivalent culture in the other, the way of analogy is usually applied to find a similar cultural phenomenon in this culture to locate the other culture, which will be more clear at a glance.

\section{Summary}

Through discussions, it can be seen that the Taishan Shigandang culture carried by the English language is both appropriate and different from the traditional Shigandang culture, and the modern expression of the traditional culture also needs the language to keep pace with the times, just as Taishan Shigandang is called "Scholar" and "doctor Shi". The translation results must be different, and today's expression of Shigandang is closer to responsibility and mission. Therefore, Kemp's translation of “stones from Taishan accept responsibilities” is more in line with the modern cultural connotation. 


\section{Conflicts of Interest}

The author declares no conflicts of interest regarding the publication of this paper.

\section{References}

Ayscough, F. W. (1917). Shrines of History: Peak of the East-T'ai Shan. Journal of the North-China Branch of the Royal ASIATIC Society, 48, 57-70.

Brown, F. (1908). Religion in Tientsin. The Methodist Publishing House.

Caulfield, J. B. (1921). At the Sacred Mountain of Shantung-Tai Shan. Northwestern Christian Advocate, 69, 1057 p.

Crow, C. (1921). The Travelers' Handbook for China. Dodd Mead \& Co.

Du, D. M. (2008). A New Theory on the Relationship between Language and Culture. Chinese Cultural Studies, 133-140.

Edmunds, C. K. (1919). Shantung, China’s Holy Land. The National Geographic Magazine, $36,241 \mathrm{p}$.

Elterich, W. O. (1894). A Chinese Goddess-Tai Shan Nai Nai or the Mother of Mountain Tai. The Church at Home and Abroad, 15, 422-423.

Geil, W. E. (1926). The Sacred Five of China. John Murray.

Hackmann, H. (1914). A German Scholar in the East: Travel Scenes and Reflections (pp. 86-89). Kegan Paul, Trench, Trübner \& Co.

Kemp, E. G. (1909). The Face of China. Duffield Company.

Moule, G. E. (1912). T'ai Shan. Journal of the North-China Branch of the Royal ASIATIC Society, 43, 1-31.

Nevius, J. (1869). China and the Chinese: A General Description of the Country and Its Inhabitants, Its Civilization and Form of Government, Its Religious and Social Institutions, Its Intercourse with Other Nations, and Its Present Ccondition and Prospects. With A Map and Illustrations (177 p.). Happer \& Brothers.

Walker, G. M. (1919). The Cradle of Chinese Civilization. ASIA, 19, 883 p.

Ye, T. (2007). Taishan Shigandang. Zhejiang People's Publishing House.

Zhou, Y. (2015). Taishan Shigandang: From Being Banned and Abolished to Carrying forward. Qilu Evening News.

https://sjb.qlwb.com.cn/qlwb/content/20150318/ArticelA21002FM.htm 